\title{
Editorial: The Ninth Rothkopf Rankings of Universities' Contributions to the INFORMS Practice Literature
}

\author{
Ronald D. Fricker Jr. \\ Operations Research Department, Naval Postgraduate School, Monterey, California 93943, \\ rdfricker@nps.edu
}

\begin{abstract}
Continuing the work begun by Michael H. Rothkopf in 1996, this paper presents the ninth ranking of universities according to their contributions to the INFORMS practice literature. Two rankings are given, each based on a different metric: visibility is the number of times a university is listed as the primary academic affiliation in the INFORMS practice literature; yield is the equivalent number of INFORMS practice papers attributable to each university based on author primary academic affiliation. As with the Eighth Rothkopf Rankings for US universities, the Naval Postgraduate School earns the top ranking for visibility and second for yield, whereas the Colorado School of Mines earns the top ranking for yield and second for visibility; for non-US universities, the University of Chile earns the top ranking for both visibility and yield.
\end{abstract}

Key words: professional: comments on.

“O perations Research is the discipline of applying advanced analytical methods to help make better decisions." So says the INFORMS website (INFORMS 2011). Note the word "applying" in the definition: operations research (OR) is an applied discipline. To promote its application, Professor Michael Rothkopf first ranked universities' contributions to the literature on INFORMS practice in a 1996 Interfaces editorial (Rothkopf 1996). The purpose of the rankings was to recognize those academics and academic institutions concerned with and active in operations research/management science (OR/MS) practice. Professor Rothkopf periodically updated the rankings (Rothkopf 1997, 1999, 2002, 2004, 2005, 2007) until his untimely passing in February 2008, after which I have continued his work (Fricker 2009).

In this paper, I update the rankings with the most recent data from 2009 and 2010. As I did in the Eighth Rothkopf Rankings, I generally follow Professor Rothkopf's approach, counting papers in Interfaces and in the OR Practice section of Operations Research. Unrefereed Interfaces columns are counted as half papers. Also following Professor Rothkopf, I use the most recent seven years of publications; in this case,
2004 to 2010. However, unlike in Professor Rothkopf's original work, I use two separate metrics-one for visibility and the second for yield; thus, I give two rankings. The visibility metric is the number of times a university is listed as the primary academic institution by the INFORMS practice literature authors. No weighting for number of coauthors or any other factor is applied, with the exception that I count Interfaces columns as half papers. The yield metric is the number of papers attributable to each university, based on authors' primary academic affiliation, with credit for each paper uniformly divided among the coauthors, and with Interfaces columns counted as half papers. See Fricker (2009) for additional discussion about the metrics.

\section{Results}

I compiled the data for 280 papers and columns published from 2004 to 2010. These consisted of 18 OR Practice papers in Operations Research, 203 papers in Interfaces, and 59 Interfaces columns. The 280 papers and columns had 541 authors with academic affiliations from 26 countries (see Table 1), of which 


$\begin{array}{lccc}\text { Australia } & \text { Cyprus } & \text { Italy } & \text { Switzerland } \\ \text { Austria } & \text { Finland } & \text { Japan } & \text { The Netherlands } \\ \text { Belgium } & \text { France } & \text { Korea } & \text { Turkey } \\ \text { Brazil } & \text { Germany } & \text { New Zealand } & \text { United Kingdom } \\ \text { Canada } & \text { Greece } & \text { Norway } & \text { United States } \\ \text { Chile } & \text { India } & \text { Spain } & \\ \text { China } & \text { Israel } & \text { Sweden } & \end{array}$

Table 1: From 2004 to 2010, 433 authors from the 26 countries listed above published 280 papers and columns in the practice literature.

392 gave US academic affiliations and 149 gave nonUS academic affiliations. The 541 authors included 433 unique individuals, one of whom had both a US and non-US academic affiliation (on different papers) sometime during 2004-2010.

\section{Visibility}

To quantify university visibility, for each of the 541 authors of the 280 papers, I simply sum the number of times a university is listed as an author's primary academic affiliation from 2004 through 2010. In so doing, coauthorship is counted equally whether an individual was the sole author or collaborated with others either within or outside of the author's university. No weighting for number of coauthors or any other factor has been applied, with the exception of counting Interfaces columns as half papers.

For example, if three authors from State University collaborated on an Interfaces paper, then State University is counted three times in the visibility rankings for that year. Similarly, if the three individuals are authors on three separate Interfaces papers (possibly with collaborators from other institutions), then State University is still counted three times. The visibility metric is essentially the number of times an academic institution is listed in print.

Table 2 shows the results for the top 43 US universities that have seven-year scores of 3.0 or higher. As with the Eighth Rothkopf Rankings, the Naval Postgraduate School ranks first, followed by the Colorado School of Mines second and the Georgia Institute of Technology third. MIT is ranked fourth, followed by the University of Maryland, College Park at fifth and the University of Southern California at sixth. Of these institutions, the top three did not change from the Eighth Rothkopf Rankings.

Table 3 shows the results for the top 13 non-US universities that have seven-year scores of 3.0 or higher.
The University of Chile ranks first; the Norwegian University of Science and Technology is second and Erasmus University Rotterdam and Lancaster University are tied for third. Laval University ranks fifth, followed by Cass Business School at sixth. Although I have continued Professor Rothkopf's tradition of ranking US and non-US universities separately, note that the University of Chile would rank 4th among US universities for visibility and the Norwegian University of Science and Technology would tie with the US universities ranked at 16th.

\section{Yield}

To quantify yield, I sum the number of times a university was listed as an author's primary academic affiliation from 2004 through 2010, weighted by the inverse of the number of coauthors. For example, for a paper with one author, that author's university received full credit for the paper; for papers with two coauthors, each university listed as the primary academic affiliation was given half credit; for a paper with three coauthors, each university listed as the primary academic affiliation was given one-third credit; etc. No other weighting was applied, with the exception of counting Interfaces columns as half papers.

Table 4 shows the results for the top 54 US universities that have seven-year scores higher than 1.0. This can be interpreted as institutions that published the equivalent of at least one INFORMS practice paper over the seven-year period. In this ranking, the Colorado School of Mines ranks first, followed by the Naval Postgraduate School second and MIT third. The University of Maryland, College Park ranks fourth, followed by the Georgia Institute of Technology at fifth and Temple University at sixth.

Table 5 shows the results for the top 16 non-US universities that have seven-year scores higher than 1.0. As in the rankings based on visibility, the University of Chile ranks first, followed by Erasmus University Rotterdam in second. The University of Toronto ranks third and Cass Business School ranks fourth. This is followed by the Lancaster University, the University of Bath, and the University of Groningen, all tied for fifth. Note that the University of Chile would rank eighth among US universities for yield, and Erasmus University would rank 13th. 


\begin{tabular}{|c|c|c|c|c|c|c|c|c|c|}
\hline \multirow[b]{2}{*}{ US university } & \multicolumn{4}{|c|}{ 2009-2010 papers } & \multicolumn{4}{|c|}{ 2004-2010 papers } & \multirow[b]{2}{*}{ Rank } \\
\hline & Int & Int C & ORP & Score & Int & Int $\mathrm{C}$ & ORP & Score & \\
\hline Naval Postgraduate School & 4 & 1 & 0 & 4.5 & 21 & 1 & 5 & 26.5 & 1 \\
\hline Colorado School of Mines & 2 & 3 & 0 & 3.5 & 10 & 13 & 0 & 16.5 & 2 \\
\hline Georgia Institute of Technology & 4 & 0 & 2 & 6.0 & 13 & 0 & 2 & 15.0 & 3 \\
\hline Massachusetts Institute of Technology & 2 & 0 & 1 & 3.0 & 8 & 4 & 1 & 11.0 & 4 \\
\hline University of Maryland, College Park & 1 & 1 & 0 & 1.5 & 7 & 5 & 0 & 9.5 & 5 \\
\hline University of Southern California & 8 & 0 & 0 & 8.0 & 9 & 0 & 0 & 9.0 & 6 \\
\hline University of Texas at Austin & 4 & 0 & 0 & 4.0 & 9 & 0 & 0 & 9.0 & 6 \\
\hline Lehigh University & 3 & 0 & 2 & 5.0 & 6 & 0 & 2 & 8.0 & 8 \\
\hline Purdue University & 0 & 0 & 0 & 0.0 & 6 & 0 & 2 & 8.0 & 8 \\
\hline Cornell University & 1 & 0 & 0 & 1.0 & 7 & 1 & 0 & 7.5 & 10 \\
\hline Boston University & 4 & 0 & 0 & 4.0 & 7 & 0 & 0 & 7.0 & 11 \\
\hline United States Military Academy & 0 & 0 & 0 & 0.0 & 7 & 0 & 0 & 7.0 & 11 \\
\hline Villanova University & 4 & 0 & 0 & 4.0 & 7 & 0 & 0 & 7.0 & 11 \\
\hline Carnegie Mellon University & 0 & 1 & 0 & 0.5 & 4 & 1 & 2 & 6.5 & 14 \\
\hline University of Dayton & 3 & 1 & 0 & 3.5 & 6 & 1 & 0 & 6.5 & 14 \\
\hline Arizona State University & 0 & 0 & 1 & 1.0 & 5 & 0 & 1 & 6.0 & 16 \\
\hline University of Connecticut, Storrs & 4 & 0 & 2 & 6.0 & 4 & 0 & 2 & 6.0 & 16 \\
\hline University of Arizona & 3 & 0 & 0 & 3.0 & 6 & 0 & 0 & 6.0 & 16 \\
\hline Temple University & 0 & 1 & 0 & 0.5 & 2 & 5 & 1 & 5.5 & 19 \\
\hline East Carolina University & 3 & 0 & 0 & 3.0 & 5 & 0 & 0 & 5.0 & 20 \\
\hline University of Cincinnati & 4 & 2 & 0 & 5.0 & 4 & 2 & 0 & 5.0 & 20 \\
\hline University of Florida, Gainesville & 1 & 0 & 0 & 1.0 & 5 & 0 & 0 & 5.0 & 20 \\
\hline University of Missouri, Columbia & 0 & 0 & 0 & 0.0 & 5 & 0 & 0 & 5.0 & 20 \\
\hline University of Pennsylvania & 0 & 0 & 0 & 0.0 & 3 & 2 & 1 & 5.0 & 20 \\
\hline University of California, Los Angeles & 1 & 0 & 1 & 2.0 & 3 & 1 & 1 & 4.5 & 25 \\
\hline Vanderbilt University & 0 & 0 & 0 & 0.0 & 4 & 1 & 0 & 4.5 & 25 \\
\hline New York University & 0 & 0 & 0 & 0.0 & 3 & 0 & 1 & 4.0 & 27 \\
\hline Pennsylvania State University, Erie & 0 & 0 & 0 & 0.0 & 4 & 0 & 0 & 4.0 & 27 \\
\hline Princeton University & 3 & 0 & 0 & 3.0 & 3 & 0 & 1 & 4.0 & 27 \\
\hline San Francisco State University & 0 & 0 & 0 & 0.0 & 4 & 0 & 0 & 4.0 & 27 \\
\hline Texas A\&M University & 2 & 0 & 0 & 2.0 & 4 & 0 & 0 & 4.0 & 27 \\
\hline Thomas Jefferson University & 4 & 0 & 0 & 4.0 & 4 & 0 & 0 & 4.0 & 27 \\
\hline University of North Carolina & 1 & 0 & 0 & 1.0 & 4 & 0 & 0 & 4.0 & 27 \\
\hline University of South Carolina & 0 & 0 & 0 & 0.0 & 4 & 0 & 0 & 4.0 & 27 \\
\hline University of Tennessee & 0 & 0 & 0 & 0.0 & 4 & 0 & 0 & 4.0 & 27 \\
\hline Indiana University & 0 & 0 & 0 & 0.0 & 3 & 1 & 0 & 3.5 & 36 \\
\hline Northwestern University & 3 & 0 & 0 & 3.0 & 3 & 0 & 0 & 3.0 & 37 \\
\hline Southern Methodist University & 0 & 0 & 0 & 0.0 & 3 & 0 & 0 & 3.0 & 37 \\
\hline University of Arkansas & 1 & 0 & 0 & 1.0 & 3 & 0 & 0 & 3.0 & 37 \\
\hline University of Colorado at Denver & 0 & 0 & 0 & 0.0 & 3 & 0 & 0 & 3.0 & 37 \\
\hline University of Michigan & 0 & 0 & 0 & 0.0 & 3 & 0 & 0 & 3.0 & 37 \\
\hline Virginia Commonwealth University & 0 & 0 & 0 & 0.0 & 3 & 0 & 0 & 3.0 & 37 \\
\hline Yale University & 1 & 0 & 0 & 1.0 & 2 & 0 & 1 & 3.0 & 37 \\
\hline
\end{tabular}

Table 2: The table lists visibility rankings for the top 43 US universities. A school's score is the total number of citations for authors listing that university as their primary affiliation in Interfaces (Int) and in the OR Practice section of Operations Research (ORP) plus half the number of unrefereed Interfaces columns (Int C). That is, Score $=\operatorname{Int}+\mathbf{O R P}+(\operatorname{Int} C) / 2$. The table shows school rankings and scores for 2004 through 2010 and scores for only 2009 to 2010.

\section{Discussion}

Expanding on Rothkopf's seminal 1996 work, this paper ranks universities according to their contributions to the INFORMS practice literature in terms of visibility (the number of times a university is listed as the primary academic affiliation in the INFORMS practice literature) and yield (the equivalent number of INFORMS practice papers attributable to each university based on author primary academic affiliation). As Tables 2-5 show, the results of the two rankings 


\begin{tabular}{|c|c|c|c|c|c|c|c|c|c|}
\hline \multirow[b]{2}{*}{ Non-US university } & \multicolumn{4}{|c|}{ 2009-2010 papers } & \multicolumn{4}{|c|}{ 2004-2010 papers } & \multirow[b]{2}{*}{ Rank } \\
\hline & Int & Int C & ORP & Score & Int & Int C & ORP & Score & \\
\hline University of Chile & 4 & 0 & 0 & 4.0 & 12 & 0 & 2 & 14.0 & 1 \\
\hline Norwegian U of Science and Technology & 3 & 0 & 0 & 3.0 & 6 & 0 & 0 & 6.0 & 2 \\
\hline Erasmus University Rotterdam & 1 & 0 & 0 & 1.0 & 5 & 0 & 0 & 5.0 & 3 \\
\hline Lancaster University & 4 & 0 & 0 & 4.0 & 5 & 0 & 0 & 5.0 & 3 \\
\hline Laval University & 4 & 0 & 0 & 4.0 & 4 & 0 & 0 & 4.0 & 5 \\
\hline Cass Business School & 0 & 2 & 0 & 1.0 & 0 & 7 & 0 & 3.5 & 6 \\
\hline University of Toronto & 0 & 1 & 0 & 0.5 & 3 & 1 & 0 & 3.5 & 6 \\
\hline Catholic University of Leuven & 2 & 0 & 0 & 2.0 & 3 & 0 & 0 & 3.0 & 8 \\
\hline Nanzan University & 0 & 0 & 0 & 0.0 & 3 & 0 & 0 & 3.0 & 8 \\
\hline Sabanci University & 0 & 0 & 0 & 0.0 & 2 & 0 & 1 & 3.0 & 8 \\
\hline Seville University & 0 & 0 & 0 & 0.0 & 3 & 0 & 0 & 3.0 & 8 \\
\hline University of Alberta & 1 & 0 & 0 & 1.0 & 3 & 0 & 0 & 3.0 & 8 \\
\hline University of Groningen & 2 & 0 & 1 & 3.0 & 2 & 0 & 1 & 3.0 & 8 \\
\hline
\end{tabular}

Table 3: The table lists visibility rankings for the top 13 non-US universities. A school's score is the total number of citations for authors listing that university as their primary affiliation in Interfaces (Int) and in the OR Practice section of Operations Research (ORP) plus half the number of unrefereed Interfaces columns (Int C). That is, Score $=$ Int + ORP $+($ Int C)/2. The table shows school rankings and scores for 2004 through 2010 and scores for 2009 to 2010 only.

are similar but not the same. For example, for US universities, the Naval Postgraduate School takes the top ranking for visibility and second for yield, whereas the Colorado School of Mines takes the top ranking for yield and second for visibility. In contrast, for nonUS universities, the University of Chile takes the top ranking for both visibility and yield.

Figures 1 and 2 display the ranking trends among the top-ranked schools (those that ranked in the top six for US universities and those that ranked in the top three and for non-US universities) for roughly the past decade. Both figures show the ebb and flow of schools over time where, for US universities, the University of Virginia, Rutgers, University of Texas at Austin, and Carnegie Mellon University (CMU) lead the earlier rankings. They were subsequently overtaken by the University of Pennsylvania and the Georgia Institute of Technology. Most recently, the Colorado School of Mines and the Naval Postgraduate School have led the rankings. Interestingly, among all US universities, only the Naval Postgraduate School has ranked in the top six for all rankings since 2002.

Similarly, for the non-US universities, the University of British Columbia and the University of Chile regularly ranked in the top three in the earlier rankings. In the later rankings, the University of Chile and
Erasmus University have been dominant. Among all non-US universities, only the University of Chile has ranked in the top three for all rankings since 2002.

\section{Operations Research Practice Papers}

In 2007, Professor Rothkopf lamented that the number of Operations Research practice papers had reached an extreme low point. Figure 3 (a tally of the number of practice papers published in Operations Research by year for the past 21 years) shows in detail what Professor Rothkopf was describing-a distinct downward trend over the past 15 years or so. For example, an average of 8.4 OR Practice papers were published per year in the 1990s (peaking in 1994 and 1995 when two or more practice papers were published per issue); from 2000 to 2008, the average was only 2.9 papers per year.

However, I am pleased to report that the trend seems to have reversed somewhat. From 2008-2010, the average number of OR Practice papers has risen to 4.3 per year, although this is still substantially below the annual average of the 1990s. Furthermore, David Simchi-Levi, Operations Research Editor-in-Chief, and Andrés Weintraub, the Operations Research Area Editor for OR Practice, write:

In the last twelve months, the OR editorial board has focused on the impact of the journal on practice. One important observation that was made is that 


\begin{tabular}{|c|c|c|c|c|c|c|c|c|c|}
\hline \multirow[b]{2}{*}{ Non-US university } & \multicolumn{4}{|c|}{ 2009-2010 papers } & \multicolumn{4}{|c|}{ 2004-2010 papers } & \multirow[b]{2}{*}{ Rank } \\
\hline & Int & $\operatorname{Int} \mathrm{C}$ & ORP & Score & Int & Int C & ORP & Score & \\
\hline Colorado School of Mines & 0.40 & 2.00 & 0.00 & 1.40 & 3.21 & 12.00 & 0.00 & 9.21 & 1 \\
\hline Naval Postgraduate School & 1.50 & 1.00 & 0.00 & 2.00 & 6.83 & 1.00 & 1.00 & 8.33 & 2 \\
\hline Massachusetts Institute of Technology & 0.33 & 0.00 & 0.50 & 0.83 & 2.99 & 2.00 & 0.50 & 4.49 & 3 \\
\hline University of Maryland, College Park & 0.14 & 0.33 & 0.00 & 0.31 & 2.68 & 3.33 & 0.00 & 4.34 & 4 \\
\hline Georgia Institute of Technology & 1.00 & 0.00 & 0.67 & 1.67 & 3.45 & 0.00 & 0.67 & 4.12 & 5 \\
\hline Temple University & 0.00 & 1.00 & 0.00 & 0.50 & 0.83 & 5.00 & 0.50 & 3.83 & 6 \\
\hline University of Dayton & 2.33 & 0.33 & 0.00 & 2.50 & 3.42 & 0.33 & 0.00 & 3.58 & 7 \\
\hline Cornell University & 1.00 & 0.00 & 0.00 & 1.00 & 2.72 & 0.50 & 0.00 & 2.97 & 8 \\
\hline University of Florida, Gainesville & 1.00 & 0.00 & 0.00 & 1.00 & 2.78 & 0.00 & 0.00 & 2.78 & 9 \\
\hline Boston University & 1.53 & 0.00 & 0.00 & 1.53 & 2.68 & 0.00 & 0.00 & 2.68 & 10 \\
\hline Dartmouth College & 0.00 & 0.00 & 0.00 & 0.00 & 2.00 & 1.00 & 0.00 & 2.50 & 11 \\
\hline Villanova University & 1.33 & 0.00 & 0.00 & 1.33 & 2.33 & 0.00 & 0.00 & 2.33 & 12 \\
\hline University of Southern California & 2.00 & 0.00 & 0.00 & 2.00 & 2.20 & 0.00 & 0.00 & 2.20 & 13 \\
\hline University of Pennsylvania & 0.00 & 0.00 & 0.00 & 0.00 & 1.17 & 1.00 & 0.50 & 2.17 & 14 \\
\hline University of Texas at Austin & 0.80 & 0.00 & 0.00 & 0.80 & 2.08 & 0.00 & 0.00 & 2.08 & 15 \\
\hline East Carolina University & 1.00 & 0.00 & 0.00 & 1.00 & 2.00 & 0.00 & 0.00 & 2.00 & 16 \\
\hline Purdue University & 0.00 & 0.00 & 0.00 & 0.00 & 1.25 & 0.00 & 0.67 & 1.92 & 17 \\
\hline San Francisco State University & 0.00 & 0.00 & 0.00 & 0.00 & 1.87 & 0.00 & 0.00 & 1.87 & 18 \\
\hline University of California, Los Angeles & 0.13 & 0.00 & 0.50 & 0.63 & 1.12 & 0.33 & 0.50 & 1.79 & 19 \\
\hline Arizona State University & 0.00 & 0.00 & 0.50 & 0.50 & 1.27 & 0.00 & 0.50 & 1.77 & 20 \\
\hline Carnegie Mellon University & 0.00 & 0.50 & 0.00 & 0.25 & 1.00 & 0.50 & 0.50 & 1.75 & 21 \\
\hline Lehigh University & 0.50 & 0.00 & 0.50 & 1.00 & 1.25 & 0.00 & 0.50 & 1.75 & 21 \\
\hline Walden University & 0.00 & 1.00 & 0.00 & 0.50 & 0.00 & 3.50 & 0.00 & 1.75 & 21 \\
\hline University of Cincinnati & 1.23 & 1.00 & 0.00 & 1.73 & 1.23 & 1.00 & 0.00 & 1.73 & 24 \\
\hline University of Arizona & 0.87 & 0.00 & 0.00 & 0.87 & 1.62 & 0.00 & 0.00 & 1.62 & 25 \\
\hline University of Missouri, Columbia & 0.00 & 0.00 & 0.00 & 0.00 & 1.60 & 0.00 & 0.00 & 1.60 & 26 \\
\hline University of South Carolina & 0.00 & 0.00 & 0.00 & 0.00 & 1.58 & 0.00 & 0.00 & 1.58 & 27 \\
\hline University of Tennessee & 0.00 & 0.00 & 0.00 & 0.00 & 1.58 & 0.00 & 0.00 & 1.58 & 27 \\
\hline George Mason University & 0.00 & 0.00 & 0.00 & 0.00 & 1.00 & 0.00 & 0.50 & 1.50 & 29 \\
\hline University of Colorado at Denver & 0.00 & 0.00 & 0.00 & 0.00 & 1.50 & 0.00 & 0.00 & 1.50 & 29 \\
\hline University of Pittsburgh & 0.00 & 0.00 & 0.00 & 0.00 & 1.50 & 0.00 & 0.00 & 1.50 & 29 \\
\hline Vanderbilt University & 0.00 & 0.00 & 0.00 & 0.00 & 1.25 & 0.50 & 0.00 & 1.50 & 29 \\
\hline Penn. State University, University Park & 0.00 & 0.00 & 0.00 & 0.00 & 0.33 & 2.00 & 0.00 & 1.33 & 33 \\
\hline Rutgers University & 0.00 & 0.00 & 0.00 & 0.00 & 0.33 & 2.00 & 0.00 & 1.33 & 33 \\
\hline Texas A\&M University & 0.50 & 0.00 & 0.00 & 0.50 & 1.33 & 0.00 & 0.00 & 1.33 & 33 \\
\hline United States Military Academy & 0.00 & 0.00 & 0.00 & 0.00 & 1.33 & 0.00 & 0.00 & 1.33 & 33 \\
\hline University of Alabama & 1.00 & 0.00 & 0.00 & 1.00 & 1.33 & 0.00 & 0.00 & 1.33 & 33 \\
\hline University of Connecticut, Storrs & 0.80 & 0.00 & 0.50 & 1.30 & 0.80 & 0.00 & 0.50 & 1.30 & 38 \\
\hline Indiana University & 0.00 & 0.00 & 0.00 & 0.00 & 1.00 & 0.50 & 0.00 & 1.25 & 39 \\
\hline New York University & 0.00 & 0.00 & 0.00 & 0.00 & 0.75 & 0.00 & 0.50 & 1.25 & 39 \\
\hline University of San Francisco & 1.00 & 0.00 & 0.00 & 1.00 & 1.00 & 0.50 & 0.00 & 1.25 & 39 \\
\hline Virginia Commonwealth University & 0.00 & 0.00 & 0.00 & 0.00 & 1.17 & 0.00 & 0.00 & 1.17 & 42 \\
\hline University of North Carolina & 0.05 & 0.00 & 0.00 & 0.05 & 1.08 & 0.00 & 0.00 & 1.08 & 43 \\
\hline Brigham Young University & 0.00 & 0.00 & 0.00 & 0.00 & 0.00 & 0.00 & 1.00 & 1.00 & 44 \\
\hline Drexel University & 0.00 & 1.00 & 0.00 & 0.50 & 0.50 & 1.00 & 0.00 & 1.00 & 44 \\
\hline Illinois Institute of Technology & 0.00 & 0.00 & 0.00 & 0.00 & 1.00 & 0.00 & 0.00 & 1.00 & 44 \\
\hline Louisiana State University & 0.00 & 0.00 & 0.00 & 0.00 & 1.00 & 0.00 & 0.00 & 1.00 & 44 \\
\hline Ohio University & 0.00 & 0.00 & 0.00 & 0.00 & 1.00 & 0.00 & 0.00 & 1.00 & 44 \\
\hline Penn. State University, Erie & 0.00 & 0.00 & 0.00 & 0.00 & 1.00 & 0.00 & 0.00 & 1.00 & 44 \\
\hline University of California, Irvine & 1.00 & 0.00 & 0.00 & 1.00 & 1.00 & 0.00 & 0.00 & 1.00 & 44 \\
\hline University of Delaware & 0.00 & 0.00 & 0.00 & 0.00 & 1.00 & 0.00 & 0.00 & 1.00 & 44 \\
\hline University of Houston & 0.00 & 0.00 & 0.00 & 0.00 & 1.00 & 0.00 & 0.00 & 1.00 & 44 \\
\hline University of North Florida & 0.00 & 0.00 & 0.00 & 0.00 & 1.00 & 0.00 & 0.00 & 1.00 & 44 \\
\hline University of Virginia, Charlottesville & 0.50 & 0.00 & 0.00 & 0.50 & 1.00 & 0.00 & 0.00 & 1.00 & 44 \\
\hline
\end{tabular}

Table 4: The table lists yield rankings for the top 54 US universities. For each category (Int: Interfaces papers; Int C: unrefereed Interfaces columns; ORP: Operations Research practice papers), papers were summed by university based on authors' primary academic affiliation, with credit for each paper uniformly divided among the authors. A school's score is the total number of its papers in Interfaces and in the OR Practice section of Operations Research plus half its number of unrefereed Interfaces columns. That is, Score $=\operatorname{lnt}+\mathbf{O R P}+(\operatorname{Int} \mathrm{C}) / 2$. The table shows school rankings and scores for 2004 through 2010 and scores for only 2009 to 2010. 


\begin{tabular}{|c|c|c|c|c|c|c|c|c|c|}
\hline \multirow[b]{2}{*}{ Non-US university } & \multicolumn{4}{|c|}{ 2009-2010 papers } & \multicolumn{4}{|c|}{ 2004-2010 papers } & \multirow[b]{2}{*}{ Rank } \\
\hline & Int & Int C & ORP & Score & Int & Int C & ORP & Score & \\
\hline University of Chile & 1.00 & 0.00 & 0.00 & 1.00 & 3.10 & 0.00 & 0.25 & 3.35 & 1 \\
\hline Erasmus University Rotterdam & 0.00 & 0.00 & 0.00 & 0.00 & 2.25 & 0.00 & 0.00 & 2.25 & 2 \\
\hline University of Toronto & 0.50 & 0.00 & 0.00 & 0.50 & 1.50 & 0.33 & 0.00 & 1.67 & 3 \\
\hline Cass Business School & 0.00 & 2.16 & 0.00 & 1.08 & 0.00 & 3.17 & 0.00 & 1.58 & 4 \\
\hline Lancaster University & 0.50 & 0.00 & 0.00 & 0.50 & 1.50 & 0.00 & 0.00 & 1.50 & 5 \\
\hline University of Bath & 0.50 & 2.00 & 0.00 & 1.50 & 0.50 & 2.00 & 0.00 & 1.50 & 5 \\
\hline University of Groningen & 0.00 & 0.00 & 0.00 & 0.00 & 1.00 & 0.00 & 0.50 & 1.50 & 5 \\
\hline Catholic University of Leuven & 0.00 & 0.00 & 0.00 & 0.00 & 1.25 & 0.00 & 0.00 & 1.25 & 8 \\
\hline University of Alberta & 0.00 & 0.00 & 0.00 & 0.00 & 1.25 & 0.00 & 0.00 & 1.25 & 8 \\
\hline Norwegian $\mathrm{U}$ of Science and Technology & 0.00 & 0.00 & 0.00 & 0.00 & 1.10 & 0.00 & 0.00 & 1.10 & 10 \\
\hline HEC-University of Lausanne & 0.00 & 0.00 & 0.00 & 0.00 & 1.00 & 0.00 & 0.00 & 1.00 & 11 \\
\hline Nanzan University & 0.00 & 0.00 & 0.00 & 0.00 & 1.00 & 0.00 & 0.00 & 1.00 & 11 \\
\hline Royal Military College of Canada & 1.00 & 0.00 & 0.00 & 1.00 & 1.00 & 0.00 & 0.00 & 1.00 & 11 \\
\hline Technion & 0.00 & 0.00 & 0.00 & 0.00 & 1.00 & 0.00 & 0.00 & 1.00 & 11 \\
\hline University of Antwerp & 0.00 & 0.00 & 0.00 & 0.00 & 0.00 & 0.00 & 1.00 & 1.00 & 11 \\
\hline University of Montreal & 0.00 & 0.00 & 0.00 & 0.00 & 1.00 & 0.00 & 0.00 & 1.00 & 11 \\
\hline
\end{tabular}

Table 5: The table lists yield rankings for the top 16 non-US universities. For each category (Int: Interfaces papers; Int C: unrefereed Interfaces columns; ORP: Operations Research practice papers), papers were summed by university based on authors' primary academic affiliation, with credit for each paper uniformly divided among the authors. A school's score is the total number of its papers in Interfaces and in the OR Practice section of Operations Research plus half its number of unrefereed Interfaces columns. That is, Score $=$ Int $+\mathbf{O R P}+$ (Int C)/2. The table shows school rankings and scores for 2004 through 2010 and scores for 2009 to 2010 only.

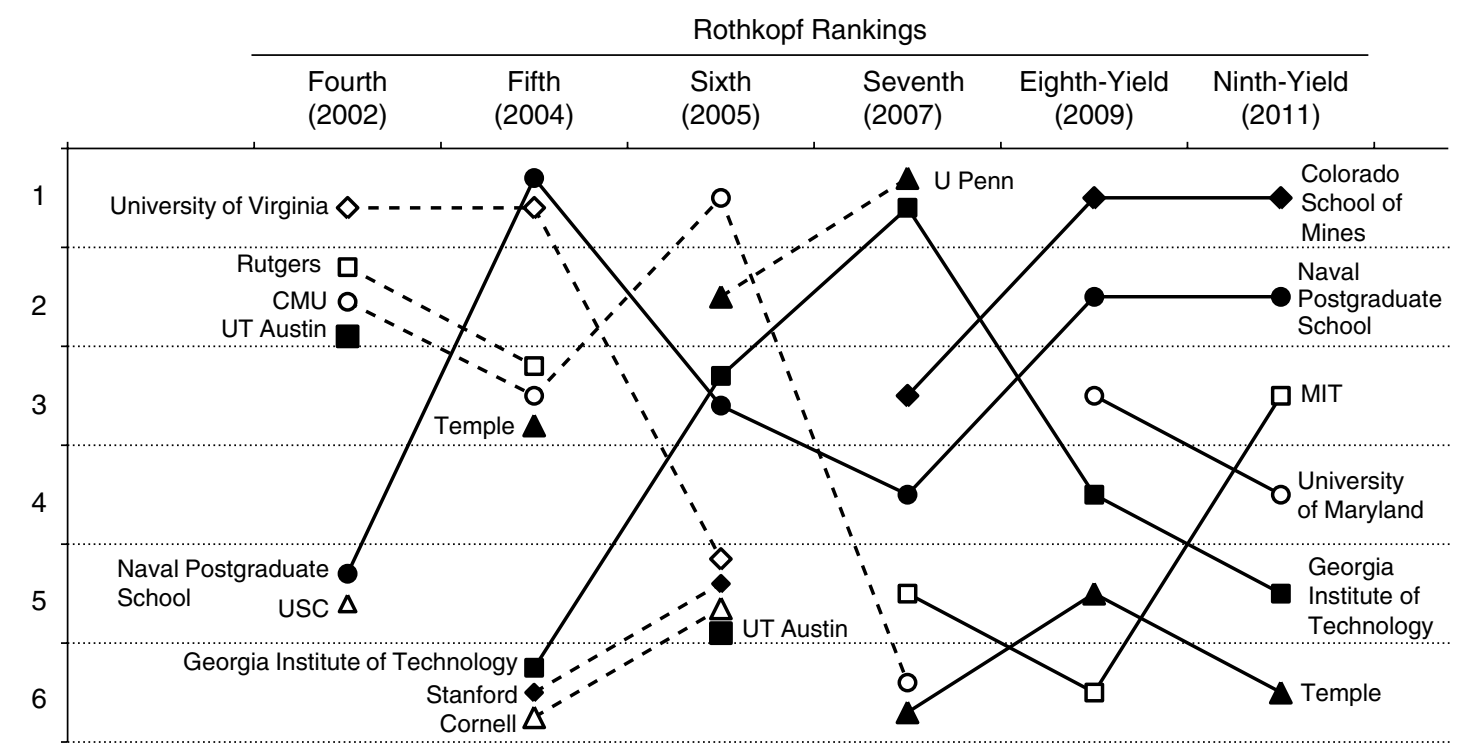

Figure 1: The graph shows the top six ranking trends among US universities for the fourth to the ninth Rothkopf Rankings. The ranks are shown on the vertical axis and the published rankings across the top (with year of publication in parentheses). Lines connect consecutive rankings in the top six by the same school. Tied ranks are denoted by multiple symbols plotted for a given rank in a particular year. 


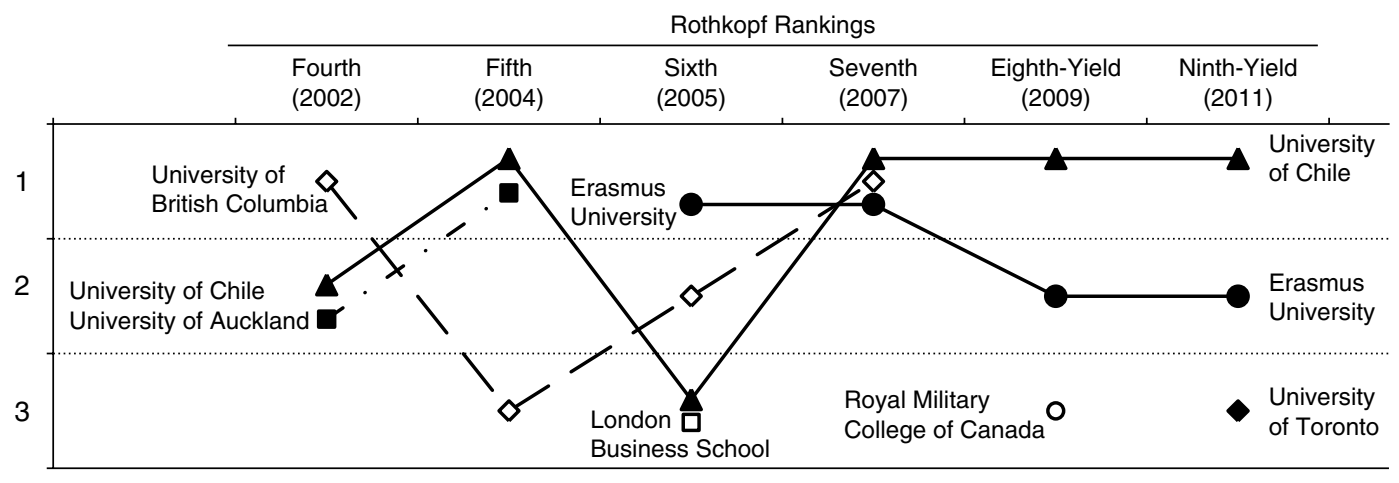

Figure 2: The graph shows the top three ranking trends among non-US universities for the fourth to the ninth Rothkopf Rankings. The ranks are shown on the vertical axis and the published rankings across the top (with year of publication in parentheses). Lines connect consecutive rankings in the top three by the same school. Tied ranks are denoted by multiple symbols plotted for a given rank in a particular year.

papers that include real data and solve real-world problems are published by the journal not necessarily in the OR Practice area. To identify those papers, Andrés Weintraub, the OR Practice Area Editor, introduced the following classifications:

- OR Practice (or "Category 1") papers: These correspond to papers that present work that has been used in practice, with reported results. Typical papers in this category are obviously papers published by the OR Practice area, though not all of them.

- Case Study (or "Category 2") papers: These are papers that present a real world, specific problem,

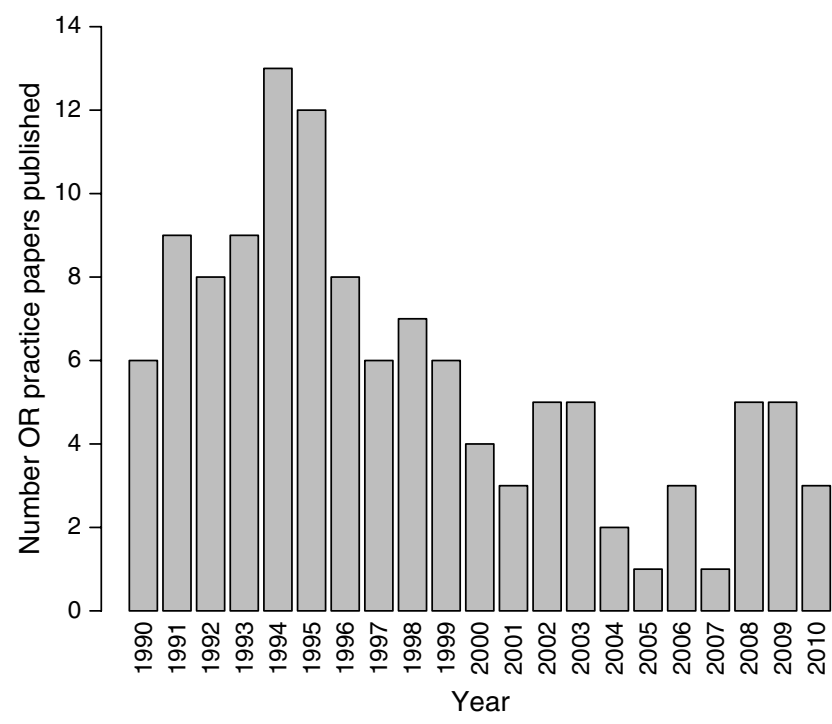

Figure 3: The graph shows the total number of $\mathrm{OR}$ Practice papers published in Operations Research by year from 1990 to 2010. with data and show how OR led to better performance. However, these results may or may not have been implemented by the firm (D. Simchi-Levi, A. Weintraub, pers. comm.)

Figure 4 depicts the trend for both OR Practice and case study papers for the past 10 years. We can see that for the past decade, OR Practice papers averaged 3.3 papers per year, whereas the case study papers averaged 3.5 papers per year. David Simchi-Levi says, "Both Andrés and I believe that this provides a better reflection of the impact of the journal on practice.

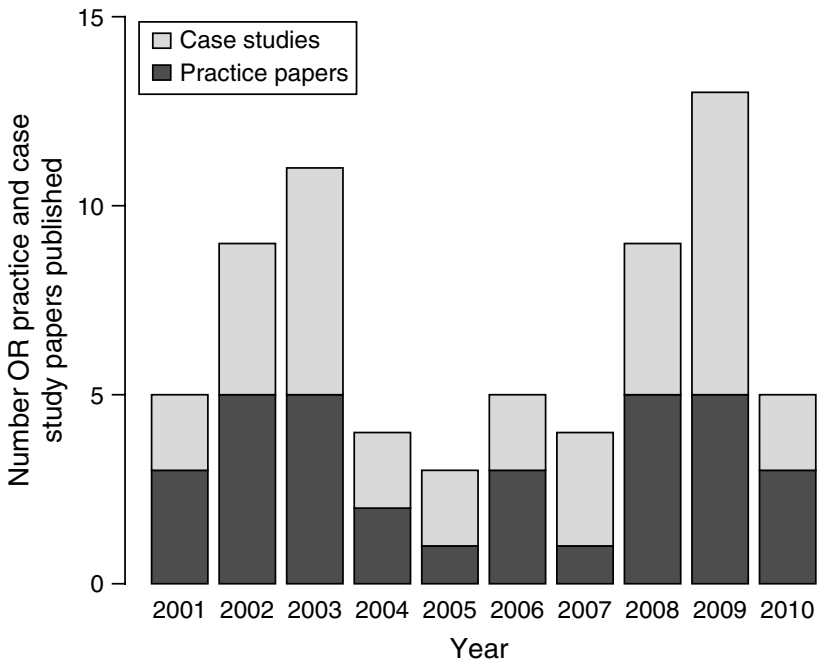

Figure 4: The graph shows the number of OR Practice and case study papers published in Operations Research by year from 2001 to 2010. 
We can of course do more to attract Category 1 and 2 papers and the board is actively looking for ways to accomplish this objective" (D. Simchi-Levi, pers. comm.).

Whether OR case study papers should be counted in these rankings is a current subject of discussion with the OR editors. Regardless, Operations Research is continuing its push to expand the publication of practice papers. As the editors say:

These papers report innovative applications of operations research to real problems together with detailed information on the impact on decision making or policy. This is consistent with the objective of the OR Practice area of the journal. Indeed, we strive to increase the number of papers published on the practice of OR in the flagship journal of our profession while maintaining high quality. Interested authors should review the submission criteria available at the URL: http:// www.informs.org/Pubs/OR/Editorial-Statements/AreaEditors-Statements/OR-Practice. We encourage authors with questions about the appropriateness of their work, even if the paper is not yet written, to contact the Area Editor to discuss the suitability of sending a paper to the OR Practice area (D. Simchi-Levi, A. Weintraub, pers. comm.).

\section{Expanding the Rankings: Decision Analysis and} Manufacturing \& Service Operations Management Since Mike Rothkopf began these rankings in 1996, a number of new INFORMS journals have been established, including Decision Analysis (DA) in 2004 and Manufacturing \& Service Operations Management (M\&SOM) in 1999. Both journals solicit and publish practice papers:

- "Decision Analysis is a quarterly journal dedicated to advancing the theory, application, and teaching of all aspects of decision analysis.... As such, the journal aims to bridge the theory and practice [emphasis added] of decision analysis, facilitating communication and the exchange of knowledge among decision analysts in academia, business, industry, and government..." (Decision Analysis 2011).

- "M\&SOM is the INFORMS journal for operations management.... The journal remains very interested in 'OM Practice' papers [emphasis added], namely, papers that report on innovative implementations of OM research to real problems or that rigorously document existing practice and demonstrate how current modeling approaches succeed or fail in practice..." (Manufacturing E Service Operations Management 2011).
Starting with the next Rothkopf Rankings, practice papers from both DA and M\&SOM will be included. Because neither journal explicitly labels practice papers as such, both Professor Stephen C. Graves, the Editor-in-Chief of M\&SOM, and Professor L. Robin Keller, the Editor-in-Chief of DA, intend to identify practice papers by including the term "practice" in a paper's key words.

Interestingly, unlike Operations Research, both DA and M\&SOM prefer not to treat or label practice papers separately from their other papers. As Steve Graves said,

Even though the M\&SOM journal no longer has a separate track for practice papers, this should not convey that we are any less interested in OM practice. Indeed, I would like to increase significantly the number of papers that report on innovative implementations of OM research to real problems or that rigorously document existing practice and demonstrate how current modeling approaches succeed or fail in practice. I believe that our field is in desperate need of such work (S. Graves, pers. comm.).

\section{Conclusions}

In this Ninth Rothkopf Rankings, the top schools were the same as in the Eighth Rothkopf Rankings, and the top-ranked schools showed little change. That should not be surprising because five out of the seven years of data are common to both rankings. That said, there are some dramatic changes in other parts of the rankings, reflecting that some schools published a lot in 2009 and 2010 and thus moved up in the rankings; other schools did not publish much after 2005 and thus moved down in the rankings. Of course, the key to making it into the top tier is regular and continued publication over the entire seven-year window.

Two years from now, these rankings will begin to include practice papers from DA and M\&SOM. The rankings will thus better reflect the breadth of the INFORMS practice literature. It will be interesting to see whether and how the new data impacts the ranks.

$\mathrm{OR}$ is at its core an applied discipline in which researchers and practitioners use quantitative methods to help improve decision making. Although the theoretical development of new methods is doubtless 
important, indeed critical, to the discipline, so too is the need for these methods to be rooted in the requirements, constraints, and messiness of real-world problems. There is no better demonstration of the utility and relevance of OR methods than their application in practice.

From my perspective, it is a bit troubling that both DA and M\&SOM have chosen not to highlight their practice papers by labeling them as such. My sense is that these journals feel that so labeling the practice papers will diminish them in some way in the eyes of academia. To the extent that academia undervalues highly visible or important applications of methods that actually improve operations, it is unfortunate and pulls OR away from its roots. This ranking, in its own small way, seeks to redress this imbalance.

\section{Acknowledgments}

My thanks to David Simchi-Levi, Andrés Weintraub, Steve Graves, and Robin Keller for their assistance and continued support of these rankings. Thanks also to Jerry Brown, Jim Eagle, Rob Dell, Dave Schrady, and an anonymous associate editor for reviewing earlier versions of this editorial and providing comments that helped to significantly improve it. Any errors or omissions are, of course, solely my responsibility.

\section{References}

Decision Analysis. 2011. Accessed August 8, 2011, http://www .informs.org/Pubs/DA.

Fricker, R. D., Jr. 2009. Editorial: The eighth Rothkopf rankings of universities' contributions to the INFORMS practice literature. Interfaces 39(6) 533-539.

INFORMS. 2011. INFORMS online. Accessed July 3, 2011, http:// www.informs.org.

Manufacturing \& Service Operations Management. 2011. Accessed August 8, 2011, http://www.informs.org/Pubs/MSOM/ Editorial-Mission.

Rothkopf, M. H. 1996. Editorial: Which universities contribute to the practice literature? The first Interfaces ranking. Interfaces 26(2) 16-21.

Rothkopf, M. H. 1997. Editorial: Which universities contribute to the practice literature? The second Interfaces ranking. Interfaces 27(4) 19-22.

Rothkopf, M. H. 1999. Editorial: The third Interfaces ranking of universities' contributions to the practice literature. Interfaces 29(6) 107-111.

Rothkopf, M. H. 2002. Editorial: Leveling the field? The fourth Interfaces ranking of universities' contributions to the practice literature. Interfaces 32(2) 23-27.

Rothkopf, M. H. 2004. Editorial: The fifth Interfaces ranking of universities' contributions to the practice literature. Interfaces 34(2) 135-138.

Rothkopf, M. H. 2005. Editorial: The sixth Interfaces ranking of universities' contributions to the practice literature. Interfaces 35(5) $425-428$.

Rothkopf, M. H. 2007. Editorial: The seventh Interfaces ranking of universities' contributions to the practice literature. Interfaces 37(6) 566-569. 